\title{
LMS AND EMPLOYEE TASK ASSIGNMENT SYSTEM APPLICATION
}

\author{
Tarun Grover \\ Department of IT \\ HMR Institute of Technology and Management, \\ Delhi, New Delhi
}

\begin{abstract}
This project is aimed at developing an online leave apply system and Employee task assignment application that is of importance to either an organization or school or an office. The Leave Application System (LMS) is an Intranet based application that can be accessed throughout the organization or a specified group/Dept. The Employee Task Assignment system is also accessible foe both employee and employer in any organization. This system can be used to automate the workflow of leave applications, and their approvals, task assignment, task completion and their tracking. The periodic crediting or debiting of leave is also automated and system dependent. There are features like email notifications, automatic approval of leave, mentor approval, functional head approval, report generators etc. in this system. Leave Application System will reduce paperwork and maintains record in more efficient way. Task assignment application also helps to maintain workflow and deadlines with proper Identification and Attendance of employees.
\end{abstract}

Keywords- Employee Task Assignment System, Leave management System

\section{INTRODUCTION}

In the existing paperwork related to leave management, leaves are maintained using the attendance register for staff of different departments. The staff needs to submit their leaves manually to their respective authorities in their respective departments. This increases the paperwork \& maintaining the records becomes tedious. Maintaining notices in the records also increases the paperwork. The main objective of the proposed system is to decrease the paperwork and help in easier record maintenance by having a particular centralized Database System, where Leaves and Notices are maintained in every department and be. The proposed system automates the existing system. It decreases the paperwork and enables easier record maintenance. It also reduces chances of Data loss. This module intelligently adapts to HR policy of the management \&allows employees and their line managers to manage leaves and replacements for better scheduling of workload. The Task assignment application basically reduces the distracted communication. It helps to assign. Edit or delete the assigned task, not completed then review and delete if completed. It

\author{
Abhimanyu Kumar \\ Department of IT \\ HMR Institute of Technology and Management, \\ Delhi, New Delhi,
}

will help to collaboratively manage all task and both can refer in future for reference. We are leaving in $21^{\text {st }}$ century where the technology is most dominant field today and we use technology everywhere like from basic calling to deal bighealth problems and we are advancing this everyday. We also follow this same in corporate and shifted work to automation. But sometimes we are not extracting the more use of technology. Like even now we are using the mail to reply for any message to our team leader of any work or project, it's a good way to communicate but not the proper way. If we have refer the things in future we go back and refer to that mail again which is time consuming and sometimes we don't get the mail. This lead a problem and we don't have idea to what to do? So if we have any solution for this than it would be greater. Our application mostly solve this because we are proposing the Task Assignment application where employers assign the task to employees and employees see that task, update it, ask about that if need any help, employer get response of employee, progress of task, and employees contribution in mean of time. We think this is a good approach that all these things are happening in an application which is accessible by both of them. Both of them refer to this task in future also in same place and again discuss, initiate, or close it as per requirements. It would be easy to handle and make productivity better which will help the organization. It would be easy to handle and make productivity better which will help the organization Employer/Manager get all details like which task assigned to whom, when assigned, ended time, progress status in a dashboard which is easy to refer and belong to that particular employer.

Our leave application system also provides many good solution to existing flow of leave application. Leave application provide the flexibility to person to apply for leave and automatically it will be counted and reduce as per company policy. Leave application provides mentor panel also so that employee apply to mentor and get the approval. Application also get the performance sheet basis on leaves applied and all approves leaved.

\section{FUNCTIONS THAT CAN BE PERFORMED}

Web Based: The devices that will access this application should be the web based. Applications can use this and 


\section{International Journal of Engineering Applied Sciences and Technology, 2021 \\ Vol. 6, Issue 1, ISSN No. 2455-2143, Pages 148-154 \\ Published Online May 2021 in IJEAST (http://www.ijeast.com)}

perform different tasks and automate process for task management as well as leave management and application.

Network Based: The devices should have an active internet connection and it is needed to be switched on and get the application working.

Working Internet: The internet should be on to access this application which will help to perform actions on the application and update data according to action performed. Internet helps to access at the same time and update data in real time when most other are accessing it and working on it.

\section{A. Related Work}

In this paper, it analyze shortcomings of the basic system, and develop and evaluate solutions to address these shortcomings. Additionally, describe several new enhancements, including a mentor panel to provide flexibility in department head by which they can allow and take decision on behalf of linemanagers and allow the leave to employee. Also we included performance sheet in employee dashboard by which employee can download and analyze the performance and remaining leaves for the same. We also automated the apply form where employee can choose for different type of leaves and no burden on mentor or line managers to specifically ask for type. Employees can also update basic information in profile section.

In the Admin panel, all the requests are there which was asked by the employees and admin has the authority to approve also. There is also the department section where admin can see specifically the department requests and work accordingly Leave type section is there which allows to check which type of leave applied by employee and collaboratively group them Also Designation and Employees data can be seen form there which will help to find out which of the department employee has requested for the leave. Mentors panel is there which allows us to see and assign the mentors in different department Functional Head Section allows to check details of all functional heads and update it. Leave application section helps to track all the employees leaves and extra leaves which was taken by people. It allows to check who the employee is on leave for particular date of who are available. Admin can change password and set new password also. And most other things are available in this application which will help the respective authorities to take look with the help of technology and run a good business.

The frequently proposed solution to allow and manage leave of employee through application and make the process paper free and consolidate to a one single place will definitely help the organization to keep track the things without any further stress. In this paper, we analyze the need of this application and how this can help in a better way to solve the organization problem and where each one is familiar with this and able to use efficiently and also mangeable. Also we keep determined

that how we can reduce the cost and implement it in better way in reduced price.

The motivation for task management application and leave application System was drawn to look at that sometimes it is tedious and not effective that we are referring every mail for the any work. It is good to communicate in a shorter way but not for the project details and tasks which the regulated and confidential. If we shift it to application it is beneficial because it provides greater and easier access with much of the details and individually we can track progress also in the application itself, discuss there or update the task status in there itself. We think it is a good approach for any big or small organization. Also leave application system helps to reduce the paperwork and stress to the line managers because we proposed the mentor panel who can allow and take decision on behalf of line managers and allow the people to take leave.

\section{B. PROPOSED SYSTEM}

This paper presents a technique to improve the workflow and management system in the organization and improve the productivity of the people and expand the business. It helps to remove paperwork and allow employees to handle leave system and work assignment system efficiently which help the admin, line managers to easily track the employee work and applications, allow their requests and discuss them properly about task and completion time with greater management details and accessibility.

\section{SOME BENEFITS ARE:}

Easily apply for the leave in the application.

Less time-consuming and efficient.

Collaborative process and easily accessible.

Get the all work related details in dashboard.

Get all the attendance details in application itself with clocked in or clocked out timings.

\section{MODULES of LEAVE APPLICATION SYSTEM \\ Dashboard \\ Department \\ Leave Type \\ Designation}

\section{1 DASHBOARD}

Dashboard in the application is built and deployed with greater aspects and information gathering. Dashboard helps us to know about various details of the admin panel like profile, mobile, address, name and many more things. Dashboard help to get overview about the admin and all the application details.

\section{C.2DEPARTMENT}

The Department module which is built here specify admin that to which department you have to switch and which department 


\section{International Journal of Engineering Applied Sciences and Technology, 2021 \\ Vol. 6, Issue 1, ISSN No. 2455-2143, Pages 148-154 \\ Published Online May 2021 in IJEAST (http://www.ijeast.com)}

you want to see details whether for employees, or managers. You can switch to different departments accordingly and perform actions as per business requirements.

\section{C.3 LEAVE TYPE}

Leave type helps us to specify that which type of leave are requested by employees. We can get to know about various leaves like earned leaves, casual leaves etc. Each type of requests segregated to these types and we can easily refer them. Also we can go to apply according to type. We go to specific type and request for leave. It will send request to that type only and line-managers or mentors approves them according to type.

\section{C.4 DESIGNATION}

In the section you can see the designation and make changes to it. Designation section only visible to admin and accessible also for updation or make changes to that section.

\section{C.5 EMPLOYEES}

Employees module helps to allow admin to see about the Employees details and departments also. Also they can track the Employees and make changes to details also according to departments. Also if new joiners are their then their details also been track and make changes to that.

\section{C.6 FUNCTIONAL HEAD}

Functional head module allow to approve the all requests for the particular department. Functional head belongs to one particular department and handling the team which is responsible for a particular project/work. Functional head performs the approval for request, raise queries regarding task, asked about progress, assign task to any person of that department.

\section{C.7 LEAVE MANAGEMENT}

Leave management module helps to manage all leaves of the employees. All requested and approved leaves are recorded and managed automatically in leave management module. This module will allow to track record and we can refer in future and see that how many peoples are not available for particular day very efficiently.

\section{C.8 MENTOR}

Mentor module is the very innovative and important module in this whole application because we all see everywhere that approvals only be given by HR manager or line managers but if line manager is not available then we authorized the mentor to approve request and then HR will approve it without any disturbance. Mentor is the one under whom you are working on. And mentor is working under line-manager so it is easy for both to lined up the things and fulfill needs.

\section{Overall Architecture}

System architecture is a conceptual design. That defines the structure and behaviour of a system. An architecture description is a formal description of a system; organize in a way that supports reasoning about the structural properties of a system. It defines the system components or building blocks and provided a plan from which products can be produced and system developed, that will work together to implement the overall in a way that supports reasoning about the structural properties of the system.

\section{REPRESENTS}

1. Leave Application Initiation

2. Request sent to Line manager/Mentor

3. Approves by manager/mentor

4. Task assigned by Manager/Department head

5. Sent and received by the Employee

6. Progress Status initiated after extensive discussion and clearance

7. Status of work update at every step

8. Completion of work reported to manager and close the task.

Elaboration

It has been divided into 3 major layers:

- Application

- Middle Layer

- Data Services

\section{APPLICATION LAYER}

This is representing the specific application such as a "LMS and Task Assignment" application. This consists of various activities and services which is using and make possible to perform Leave Application successfully and Task Assignment accurately without any indiscrepency. It consists of task assignment, progress tracking, time management, work sheet, Manage Attendance, apply leave, my profile and any more functions we can perform.

\section{MIDDLE LAYER}

It provides the internal functionalities happening inside the application. Leave application system provides the functionality to apply leave and it assign to mentor/manager to approve internally and employees gets the nod from them like that without any hustle and mistake. It also tracks total leaves and remaining leaves and accordingly reduce or extend. Employee also see performance sheet which is automatically generated document according to his/her performance. Task management system helps to assign the task to employee and automatically all the details send to particular's person's account and that will see and start working on. We can also manage timings, work sheet, attendance according to clocked in or clocked out modules implemented in employee dashboard.

\section{TASK ASSIGNMENT}

This component stores the overall details about the tsk which will be assigned by the employer to employee. Task assignment module provides a form type displaying which Task title, description, date, assign to, status should fill by 


\section{International Journal of Engineering Applied Sciences and Technology, 2021 \\ Vol. 6, Issue 1, ISSN No. 2455-2143, Pages 148-154 \\ Published Online May 2021 in IJEAST (http://www.ijeast.com)}

employer and sent it to employee. This component would typically support the following functionality:

1. Trace the every task status which were assigned to different employee.

2. Perform action according to task status. Delete it if completed or make changes if required and send it again to same or different who you want to assign to resolve that issue.

3. Check all the list of task which are going on in a very segregated and customized mode.

4. Able to assign new task to employee form there also using "assign new task button".

\section{ATTENDANCE}

This component provides the details of every employees who had task assigned about the attendance. It provides the Intime which specify when work is started by person, out-time specify when person close the work for the day, total duration specify how many hours a day person spent for that work in a day. It all display in attendance section with all these details.

\section{ADMINISTRATION}

This component performs a check on work assignment/Task management by employer to employee. Administration look after the work and how it is going on and what are left for to do in that.

Web application provides access to the above components to facilitate the implementation of following services or subcomponent to verify the work and smooth completion of project in the given deadline.

- Head of Department

- Project Head

- Line Managers

\section{LEAVE TYPE MANAGE}

Leave type introduced in the application to introduce the which type of leave employee wants to get. It will allow to employee as well as employer to easily identify in which I have to apply and in which to check by employer. It reduced the burden to again and again communication between both to clear about reason and type of leave.

\section{MENTOR}

Mentor is the person which are assigned by line managers to the group of 2or 3 peoples who are new to organization and not much know about workflow. Mentor assists to these people and solve query to them if any. Mentor workflow designed to not burden online manager and it thas the authority to allow the employee request.

It would allow to accept and approve request of employee and as soon as possible the requests should solve and we can approve the functionality of mentor or reduce from the line manager side.

\section{FUNCTIONAL HEAD}

Functional head represents the head part for any project or department. It is the person who allow the project to be handle and work to assign the task to every other people of its team. Functional head is like Project Manager or line manager who are responsible for the all project completion to deployment and need to work extensively to make the product good and bug free.

\section{REST API IN PHP}

API help to implement the features and authentication easily with the request and get the results of request. REST API's implemented in any application with configuration of the URL and data which we want to request or send for computing.

\section{DATA BINDING AND PASSING}

Data binding and passing in the application will help to accurate data should be used in the application and bind the data according to the user. Every employee should be used as a unique entity and will work as a asset for the organization in their own way. We bind the leave application data by using the data passing in function and bind it with unique ids of employees.

\section{E. Implementation and Result}

Web Application development includes implementation of application features, build essential work related feature and use the required technologies with efficiently

\section{SYSTEM REQUIREMENTS}

It is required the Web application to be properly connected with data base and should be properly implemented to the system. Web application is accessible through an URL and employee need to login through their unique employee ID and se that application as per their requirements. It can be same for admin to login through their unique ID and they will get the different interface according to them with more accessibility. Employers/Managers also go to the portal and login with their ID and get the different interface with more functionalities and accessibility. Secondly, It can also be accessible to phone and we can easily do the whole things on our mobile phone as well.

\section{APPLICATION FEATURES}

Web application provides many features to implement it a soon as possible in any small organization. Leave application System helps to manage leaves without any paperwork and any admin/ hr interfare. Employees can get the leaves by approval of their line managers or mentors as well. No extra burden to senior people of organization. Also automatically counted leaves allows the employee to apply to that much available leaves and when all exhausted, it will not able to 
apply to any leave. So employee can track of their leave and apply accordingly.

Task assignment system also provides several features like Managing the task and workflows. You can assign new task form the dashboard. Perform different task to that task like update that task details, delete the task, check status of task, etc. Task assignment provides the attendance tracking to the employee to check when the person logged in or logged out. Allows administration to check all the activities between managers and employees so that all the chain of work keep going smoothly and no kind of issues raised.

\section{TECHNOLOGIES}

The Web application "LMS and Task Assignment application" is programmed in HTML, CSS and PHP using the Notepad++ Software. We have used the Software Development Kit to implement our logic into a full fledge application.

For web application, we used HTML (Hyper Text Markup Language), CSS (Cascading Styles Sheets), Bootstrap 5, PHP and implemented both Front-end and Back-end.

Some of the development environment's used are Netbeans for Web application, Android Studio, Google chrome is used for displaying the contents.

\section{DATABASE}

We have used PhpMyAdmin for our database because it provides us SQL features and storage availability. We have built database using SQL command and table also. We are storing data of users, task assigned data, leaves data, ID's and passwords, Functional head, mentor, department details, and many more.

\section{Data Flow Diagram}

\section{Employee Leave Management System Data Flow}

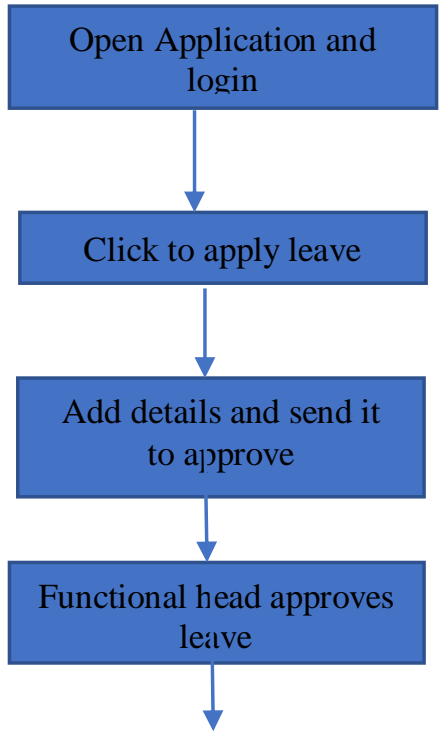

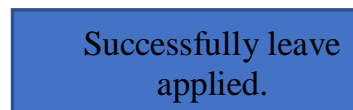

Task Assignment Application Data-Flow Diagram

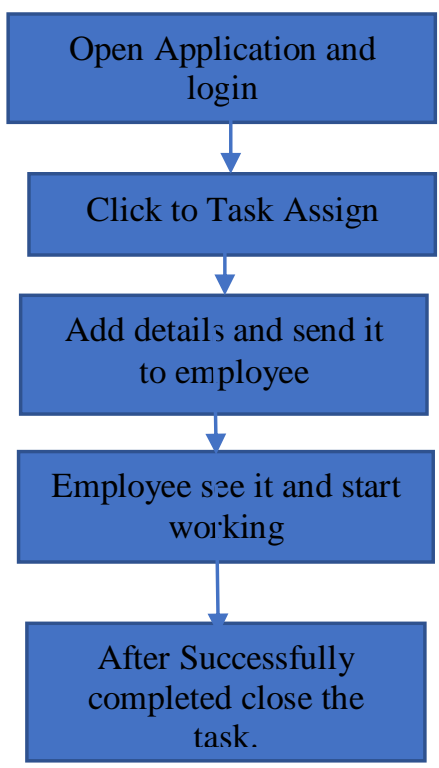

\section{F. Result and Output}

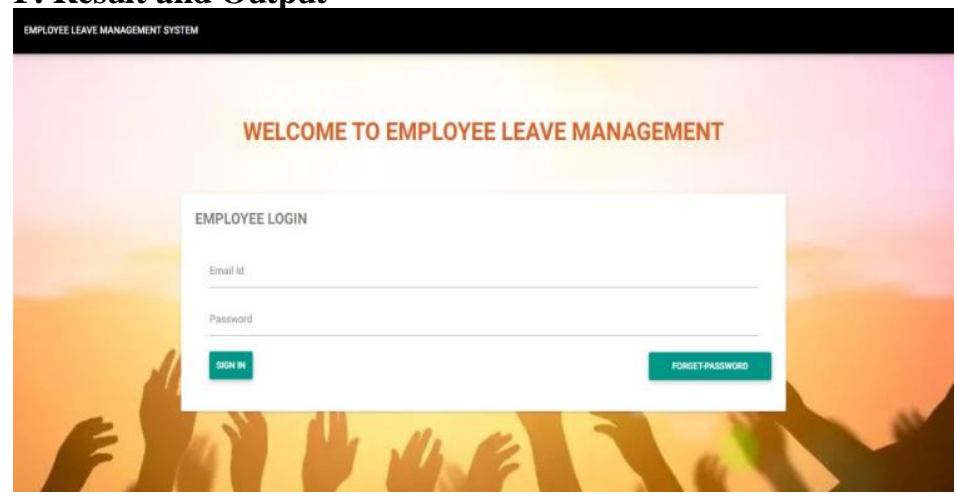

Fig: Employee Leave System Welcome Page 
International Journal of Engineering Applied Sciences and Technology, 2021

Vol. 6, Issue 1, ISSN No. 2455-2143, Pages 148-154

Published Online May 2021 in IJEAST (http://www.ijeast.com)

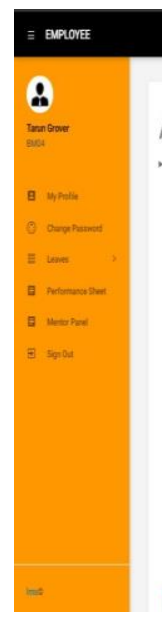

Fig: Employee Page for Leave apply

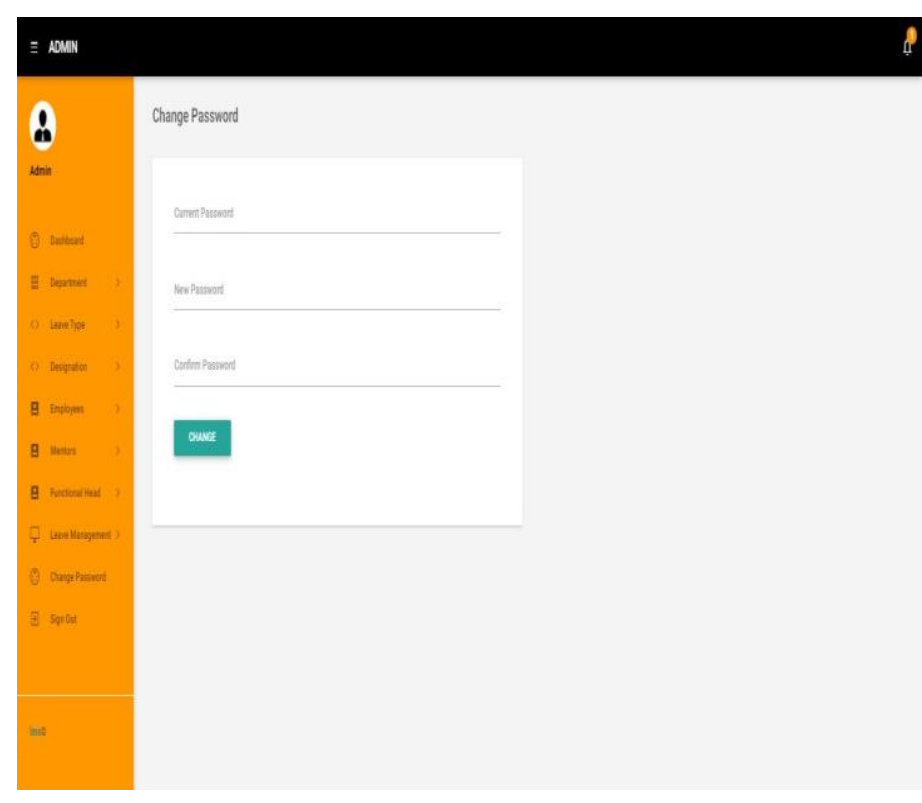

Fig: Leave Page for Admin

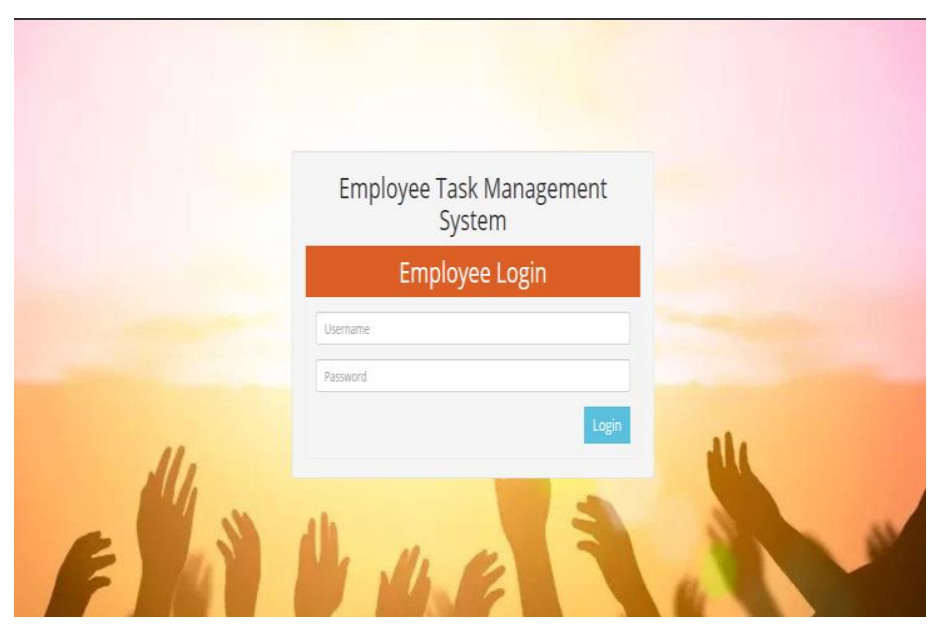

Fig: Welcome Page of Task Assignment System.
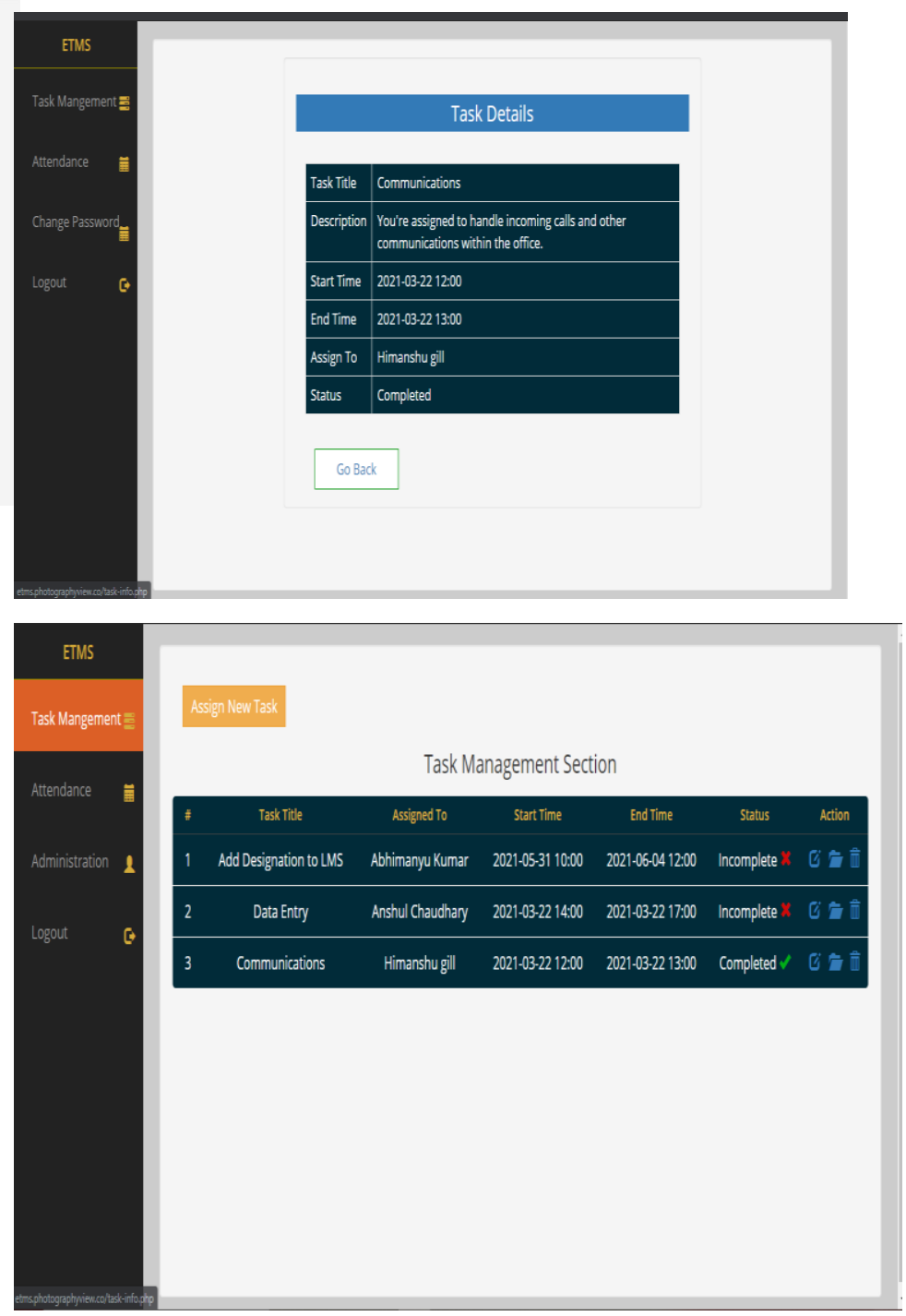

\section{CONCLUSION}

This paper presents web application to manage leave and task assignment between employer and employee. This application deploys a management function by which leave management done very easily without any paperwork and data loss. Also data is manageable very efficiently and workflow is designed help us to properly implement process without any redundancy The task assignment application uses the employee details as well as employer to interact between them, which will help to manage work easily and track progress of report efficiently. Task assignment application performs assign task, update progress, edit task details, manage attendance. It provides proper way of communication and mange things very efficiently. Now we can work on it to advance the features and implement it for various organizations based on their requirement and needs. This will 


\section{International Journal of Engineering Applied Sciences and Technology, 2021 \\ Vol. 6, Issue 1, ISSN No. 2455-2143, Pages 148-154 \\ Published Online May 2021 in IJEAST (http://www.ijeast.com)}

help to reduce burden and paperwork in offices and efficiently move to digital world.

This application is currently for web based but as technology evolving day by day, the application will also be made for other OS as well. Future scope of our application is to make it available for other as platforms as well and currently it uses an active internet connection for all the steps, we will look forward to make it more convenient and implement more different exciting features which will help in organizations to move to digital.

\section{REFERENCE}

[1] Singh Pratik Udayshankar, Fartyal Hemant Singh, Zubair Khan Abdul Ahad (2019), Employee management System, in IRJET (2019), (Pg-No. 188-192)

[2] Centralized Employee Information, Retrieved: July 8th, 2014.From:https://www.zoho.com/people/employee ma nagement-system.

[3] A.S.SyedNavaz, A.S.SyedFiaz, C.Prabhadevi, V.Sangeetha, S.Gopalakrishnan, "Human Resource Management System", IOSR Journal of Computer Engineering (IOSR-JCE), Volume 8, Issue 4 (Jan. - Feb. 2013) Page 62-71.

[4] TECH HRM (Human Resource Management System), Retrieved: November 4, 2013. From: http://www.techjetsolutions.com/brochure/TECHHRM. pdf

[5] Zhiming, L, July 2002 ,Object-Oriented Software Development with UML Retrieved: July 16th 2010. From: ttp://www.iist.unu.edu/www/docs/techreports/repor ts/report259.pdf 67

[6] Kaushik Vikrant Kumar, Gupta Arjun Kumar, Kumar Ashish, Prasad Abhishek, 2017, IJARIIE, (Pg.No-124131), http://ijariie.com/AdminUploadPdf/Student_Leave_Mana gement_System_ijariie6549.pdf

[7] M.K.P Basheer and C.V. Raghu, "Fingerprint Attendance System for classroom needs", in Proc. India Conference (INDICON),2012 Annual IEEE, pp. 433-438,7-9 December 2012

[8] Choudhary Nameera, Khalfe Aynas, Khan Yaman, Mukhtar Ansari, 2020, in International Research Journal of Engineering and Technology (IRJET), (Pg.No.17151717),https://www.irjet.net/archives/V7/i3/IRJETV7I3324.pdf

[9] S Selvi, Manas Rath, N K Sinha, S P Singh, N N J Hemrom, A Bhattacharya, A K Biswal, "HR e-Leave Tour Management System at RDCIS, SAIL International Conference on Information Technology, [June 2014]

[10] https://ieeexplore.ieee.org/document/8281931
[11] Pandore Yogesh Bandopant ,"E-Notifier: Transport Information Services in Colleges and Exploring Mobile Notification Journal of Advanced Research in Computer and Communication Engineering Vol.5, Issue 4",[April 2016]

[12] Avison, D. and Fitzgerald, G, 2003. Information systems Development Methodologies, Techniques and Tools, 3rd Edition, McGraw-Hill Education Limited, Berkshire

[13] ASP.NET, 2010. Retrieved: July 9th 2010, from: http://www.startvbdotnet.com/aspsite/asp/

[14] Introducing JSON, Retrieved: June 21, 2014, from: http://www.json.org. 